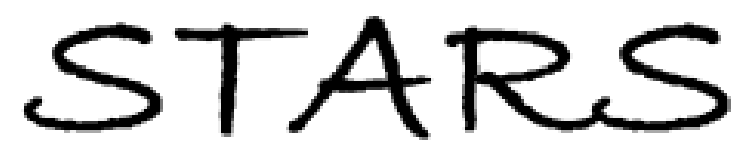

University of Central Florida

STARS

$1-1-2002$

\title{
X-ray photoelectron spectroscopic investigation of surface chemistry of ternary As-S-Se chalcogenide glasses
}

\author{
Wenyan Li \\ University of Central Florida \\ Sudipta Seal \\ University of Central Florida \\ Cedric Lopez \\ University of Central Florida \\ Kathleen A. Richardson \\ University of Central Florida
}

Find similar works at: https://stars.library.ucf.edu/facultybib2000

University of Central Florida Libraries http://library.ucf.edu

This Article is brought to you for free and open access by the Faculty Bibliography at STARS. It has been accepted for inclusion in Faculty Bibliography 2000s by an authorized administrator of STARS. For more information, please contactSTARS@ucf.edu.

\section{Recommended Citation}

Li, Wenyan; Seal, Sudipta; Lopez, Cedric; and Richardson, Kathleen A., "X-ray photoelectron spectroscopic investigation of surface chemistry of ternary As-S-Se chalcogenide glasses" (2002). Faculty Bibliography 2000s. 3316.

https://stars.library.ucf.edu/facultybib2000/3316

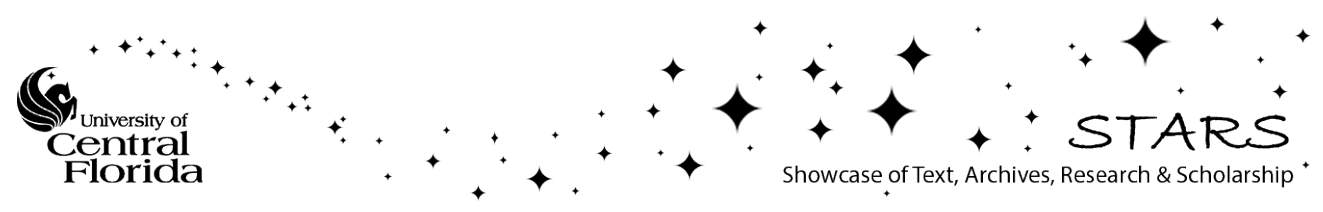




\section{X-ray photoelectron spectroscopic investigation of surface chemistry of ternary As-S-Se chalcogenide glasses}

Cite as: Journal of Applied Physics 92, 7102 (2002); https://doi.org/10.1063/1.1518134

Submitted: 31 May 2002 . Accepted: 06 September 2002 . Published Online: 27 November 2002

Wenyan Li, Sudipta Seal, Cedric Lopez, and Kathleen A. Richardson

\section{ARTICLES YOU MAY BE INTERESTED IN}

Role of $S$ / Se ratio in chemical bonding of As-S-Se glasses investigated by Raman, $\mathbf{x}-$ ray photoelectron, and extended x-ray absorption fine structure spectroscopies

Journal of Applied Physics 98, 053503 (2005); https://doi.org/10.1063/1.2009815

Study of Ga incorporation in glassy arsenic selenides by high-resolution XPS and EXAFS The Journal of Chemical Physics 142, 184501 (2015); https://doi.org/10.1063/1.4919947

Structural paradigm of Se-rich Ge-Se glasses by high-resolution x-ray photoelectron spectroscopy

Journal of Applied Physics 105, 103704 (2009); https://doi.org/10.1063/1.3130608

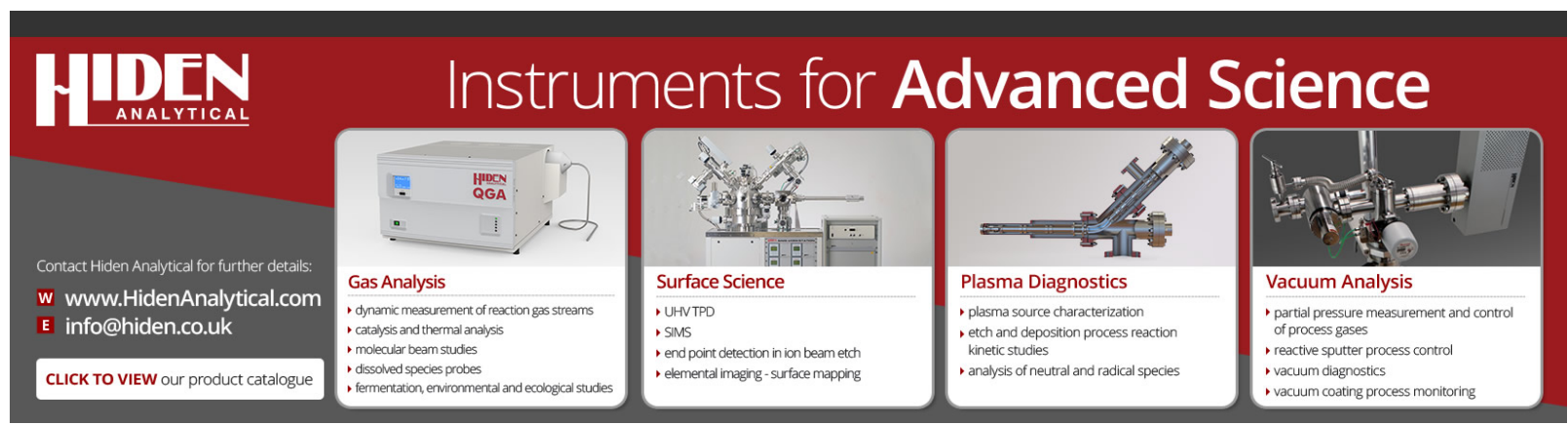




\title{
X-ray photoelectron spectroscopic investigation of surface chemistry of ternary As-S-Se chalcogenide glasses
}

\author{
Wenyan Li and Sudipta Seal ${ }^{\mathrm{a})}$ \\ Advanced Materials Processing and Analysis Center and Mechanical, Materials and Aerospace \\ Engineering, University of Central Florida, Orlando, Florida 32816
}

Cedric Lopez

School of Optics and The Center for Research and Education in Optics and Lasers, University of Central Florida, Orlando, Florida 32816

Kathleen A. Richardson

Advanced Materials Processing and Analysis Center and Mechanical, Materials and Aerospace Engineering, University of Central Florida, Orlando, Florida 32816 and School of Optics and The Center for Research and Education in Optics and Lasers, University of Central Florida, Orlando, Florida 32816

(Received 31 May 2002; accepted 6 September 2002)

\begin{abstract}
Chalcogenide glasses belong to an important class of materials, due to their good infrared transmission, and low-phonon energy as compared to other oxide glasses. Structural and chemical variations imposed by glass processing conditions, e.g., film deposition, can lead to changes in the linear and nonlinear optical properties. X-ray photoelectron spectroscopy (XPS) has been employed to study As-S-Se glasses of differing chemical compositions, in the film and the bulk form, to understand any variations in chemical bond configuration and their electronic structure. The molecular environments of $\mathrm{As}$ and $\mathrm{Se}$ for As-S-Se samples with varying $\mathrm{S} / \mathrm{Se}$ ratio (fixed As content) and As content (fixed S/Se ratio) are studied by monitoring the XPS chemical shifts. The surface chemistry of the bulk and thin-film chalcogenide glasses are also compared to determine the effect of glass processing conditions for better chalcogenides for potential waveguide applications. (C) 2002 American Institute of Physics. [DOI: 10.1063/1.1518134]
\end{abstract}

\section{INTRODUCTION}

Chalcogenide glasses have attracted considerable interest due to their infrared transparency, low-phonon energies, and high-nonlinear optical parameters. ${ }^{1-5}$ They are promising materials for grating and switching devices, and optical memories. ${ }^{6-9}$ Recently, these glasses have been used as core materials for high-efficiency fiber amplifiers due to their high-refractive indices and very low-phonon energy. ${ }^{10,11}$

Among chalcogenide glasses, the As-S-Se system is characterized by a large glass formation domain ${ }^{12}$ and distinguished nonlinear properties. ${ }^{4}$ The wide range of glass composition makes this glass an ideal candidate for tailoring important optical properties. ${ }^{4}$ The ease of glass formation makes it desirable for low-loss optical applications. Crystalline structure in glass is one of the major reasons for optical loss.

In this context, studies of chemical and structural properties of As-S-Se glasses with different compositions are vital for understanding their optical and electronic properties. Numerous researchers have documented the molecular structure of the binary glasses in As-S, ${ }^{13} \mathrm{As}-\mathrm{Se},{ }^{14}$ and $\mathrm{Se}-\mathrm{S}$ (Ref. 15) systems. To best describe the structure of the As-S glass system, the chemically ordered network $(\mathrm{CON})$ and the covalent random network are compared. Many researchers ${ }^{13}$

\footnotetext{
a) Author to whom correspondence should be addressed; electronic mail: sseal@pegasus.cc.ucf.edu
}

have concluded that statistical knowledge of chemical bonding is the key to understand the compositional dependence of the physical and optical properties of As-S glasses. Wang et al. adopted the CON model to represent the structure of the As-S-Se system. ${ }^{16}$ From the CON model that favors lower-energy bonds, Wang et al. proposed the following three assumptions: First, only As-As, As-Se, and As-S bonds are present in arsenic-rich glass; second, As-Se, As-S, and $\mathrm{Se}-\mathrm{Se}$ bonds are present in selenium-rich glass; and third, As-Se, As-S, and $\mathrm{S}-\mathrm{S}$ bonds are present in sulfur-rich glasses. While CON is believed to be the model that better represents an As-S-Se three-dimensional structure, the existence of $\mathrm{Se}-\mathrm{Se}$ in the sulfur-rich glass cannot be ruled out. According to Protasova et al. ${ }^{15}$ while introducing As in S-Se glass, arsenic mainly reacts with sulfur, resulting in the formation of $\mathrm{AsS}_{3 / 2}$ pyramids. It is also suggested that, when the amount of $\mathrm{S}$ atoms is sufficient to form bonding with all the As atoms, only the $\mathrm{AsS}_{3 / 2}$ pyramid is present in the glass network. The Se atoms exist in the $\mathrm{Se}-\mathrm{Se}$ or $\mathrm{Se}-\mathrm{S}$ chains.

In the As-S-Se ternary system, the structure and properties of $\mathrm{As}_{40} \mathrm{~S}_{60-x} \mathrm{Se}_{x}$ has been largely studied. ${ }^{17,4}$ It possesses classic $\mathrm{As}_{2} \mathrm{Ch}_{3}$ structure, where Ch represents the chalcogen atom. Wang et al. ${ }^{16}$ attempted to find the structural change with Se replacing $\mathrm{S}$ in the $\mathrm{As}_{2} \mathrm{Ch}_{3}$. However the glass composition $\left(\mathrm{As}_{40} \mathrm{~S}_{60-x} \mathrm{Se}_{x}\right)$ was in weight percentage rather than molar substitution. It is not clear that whether 


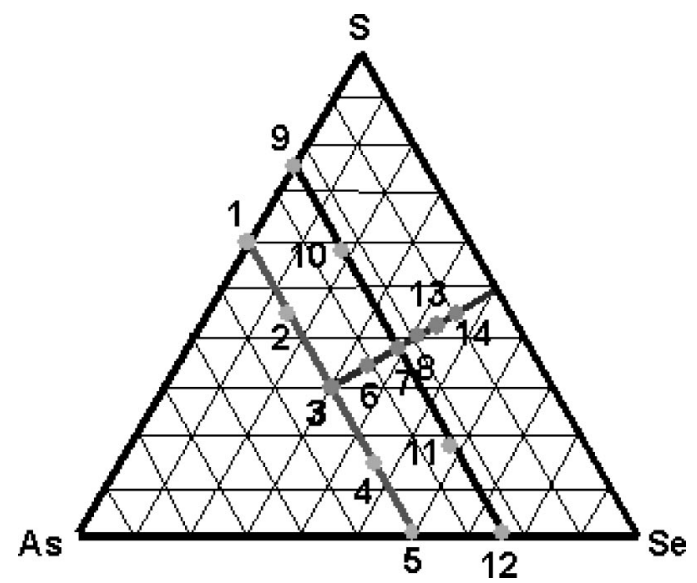

FIG. 1. The ternary composition diagram of As-S-Se system. The composition on the diagram is as follows: 1- $\mathrm{As}_{40} \mathrm{~S}_{60} ; 2-\mathrm{As}_{40} \mathrm{~S}_{45} \mathrm{Se}_{15}$; $3-\mathrm{As}_{40} \mathrm{~S}_{30} \mathrm{Se}_{30} ; 4-\mathrm{As}_{40} \mathrm{~S}_{15} \mathrm{Se}_{45} ; 5-\mathrm{As}_{40} \mathrm{~S}_{60} ; 6-\mathrm{As}_{32} \mathrm{~S}_{34} \mathrm{Se}_{34} ; 7-\mathrm{As}_{24} \mathrm{~S}_{38} \mathrm{Se}_{38}$; $8-\mathrm{As}_{18} \mathrm{~S}_{41} \mathrm{Se}_{41} ; 9-\mathrm{As}_{24} \mathrm{~S}_{76} ; 10-\mathrm{As}_{24} \mathrm{~S}_{57} \mathrm{Se}_{19} ; 11-\mathrm{As}_{24} \mathrm{~S}_{19} \mathrm{Se}_{57} ; 12-\mathrm{As}_{24} \mathrm{Se}_{76} ;$ $13-\mathrm{As}_{14} \mathrm{~S}_{43} \mathrm{Se}_{43}$; and $14-\mathrm{As}_{10} \mathrm{~S}_{45} \mathrm{Se}_{45}$.

the substitution of $\mathrm{S}$ by $\mathrm{Se}$, or the variation of As/chalcogen ratio caused the structural change.

While the material composition plays a critical role, the fabrication process of the glass also influences the structure of these chalcogenides. Two processes, melt quenching and vapor deposition are compared in this study. The melt quenching process has been used to synthesize many amorphous chalcogenides, ${ }^{18}$ and vapor deposition has been widely applied for thin-film fabrication. ${ }^{19}$ The molecular configuration of the high-temperature vapor during depositing has been studied, ${ }^{20}$ and the corresponding structure of vapordeposited film is dominated by constituent molecular species of the vapor phase. ${ }^{4}$ Hence, the possible composition and structure variation in the film as compared to the parent bulk glass cannot be ignored and requires further investigation.

$\mathrm{X}$-ray photoelectron spectroscopy (XPS) is a useful surface analytical technique to the study of chemical state and local environment of an atom. ${ }^{21-23}$ Important progressive alterations in chemical bonding are often realized through correlation with chemical shifts in the XPS binding energies of key elements. ${ }^{21-23}$ For example, XPS studies have shown systematic chemical shift in oxide, nitride, and halide systems. $^{24,25}$ XPS and x-ray emission spectroscopy have been used as complementary methods to study the electronic structure of $\mathrm{Tl}_{2} \mathrm{~S}-\mathrm{Sb}_{2} \mathrm{~S}_{3}$ (Ref. 26) and copper chalcogenides. ${ }^{27}$ In situ XPS has been shown useful in the study of the light-induced changes in As-Se glasses. ${ }^{28}$ Other chalcogenide thin films, such as $\mathrm{Ge}-\mathrm{Sb}-\mathrm{S}$ and $\mathrm{As}-\mathrm{Se}-\mathrm{Cu}$, have also been studied using XPS. ${ }^{29,30}$

In this study, XPS is applied to determine systematic chemical alternations in the chemical bonding and structure of As-S-Se glass with varying composition. The differences in the chemical structure between the bulk and the thin-film As-S-Se glasses are also examined and compared.

\section{EXPERIMENT}

\section{A. Sample preparation}

Materials were prepared according to an As-S-Se ternary diagram (Fig. 1), with either fixed S/Se ratio (varying
As concentration), or fixed As content (varying S/Se ratio). These compositions were selected based on our understanding of As-S-Se glass structure and the unique nonlinear optical property of chalcogen rich As-S-Se composition $\left(\mathrm{As}_{24} \mathrm{~S}_{38} \mathrm{Se}_{38}\right){ }^{4}$

Bulk chalcogenide glass $(\mathrm{ChG})$ samples were prepared by conventional melt quenching in an evacuated silica ampoule, and the details are described elsewhere. ${ }^{4}$ Annealed ChG samples were removed from the ampoule, cut, ground, and polished using a BUEHLER polishing machine. Bulk sample size was $10 \mathrm{~mm}$ in diameter, nominally $2 \mathrm{~mm}$ in average thickness.

Films were prepared by thermal evaporation on a slowly rotating oxidized silicon $\left(\mathrm{SiO}_{2} / \mathrm{Si}\right)$ wafer. The evaporation rate was $1-2 \mathrm{~nm} / \mathrm{s}$ and the pressure was $2 \times 10^{-7}$ Torr. Small pieces of bulk glass prepared by the technique described above were used as the target material for film fabrication. Further details are described in Ref. 31.

\section{B. XPS analysis}

Surface chemistry of the bulk and the film samples was studied using a PHI 5400 ESCA at a vacuum of $\sim 10^{-9}$ Torr. A nonmonochromatic $\mathrm{Mg}-\mathrm{K}_{\alpha}$ x-ray source $(\mathrm{h} \nu$ $=1253.6 \mathrm{eV}$ ) at a power of $250 \mathrm{~W}$ was used for the analysis. Both survey scans and individual high-resolution scans were recorded. The survey scans were conducted from 0 to 1100 $\mathrm{eV}$ with a pass energy of $44.75 \mathrm{eV}$, step of $0.5 \mathrm{eV}$, and 4 sweeps. Individual high-resolution spectra (As $3 d 5, \mathrm{C} 1 s$, $\mathrm{S} 2 p 3$, Se $3 d 5$, valance band) were conducted with a pass energy of $35.75 \mathrm{eV}$, step size $0.1 \mathrm{eV}$, and sweep number ranging from 20 to 50 to reach a satisfactory signal-to-noise ratio.

For insulators such as glasses, the charging effect can vary from sample to sample. As a result, the measurement of the absolute binding energy of the electrons from a specified energy level is not reliable. The $\mathrm{C} 1 s$ line from either the adventitious hydrocarbon or intentionally added graphite powder on the surface has been widely used for charge referencing ${ }^{11,32,33}$ For this study, the adventitious carbon was used as a reference, and the binding energy of the reference $\mathrm{C} 1 s$ line was set as $284.6 \mathrm{eV}^{34}$ For each sample, a calibration factor was calculated from the difference between the measured C $1 s$ binding energy and the reference value 284.6 $\mathrm{eV}$. The original binding energy data were corrected accordingly based on the calibration factor.

\section{RESULTS AND DISCUSSION}

\section{A. XPS survey results of As-S-Se glasses}

A typical survey of As-S-Se glass is shown in Fig. 2. It is to be noted that the only features above $600 \mathrm{eV}$ are the Auger peaks for $\mathrm{C}$ and $\mathrm{O}$. Both carbon and oxygen come from the surface contamination of the samples. No oxide formation is detected, as there is no observable peak separation for either As or Se individual scans. Both As and Se has many Auger peaks and energy-loss bands (see Fig. 2). The detail information about the binding energies of all those peaks can be found in Ref. 35. 


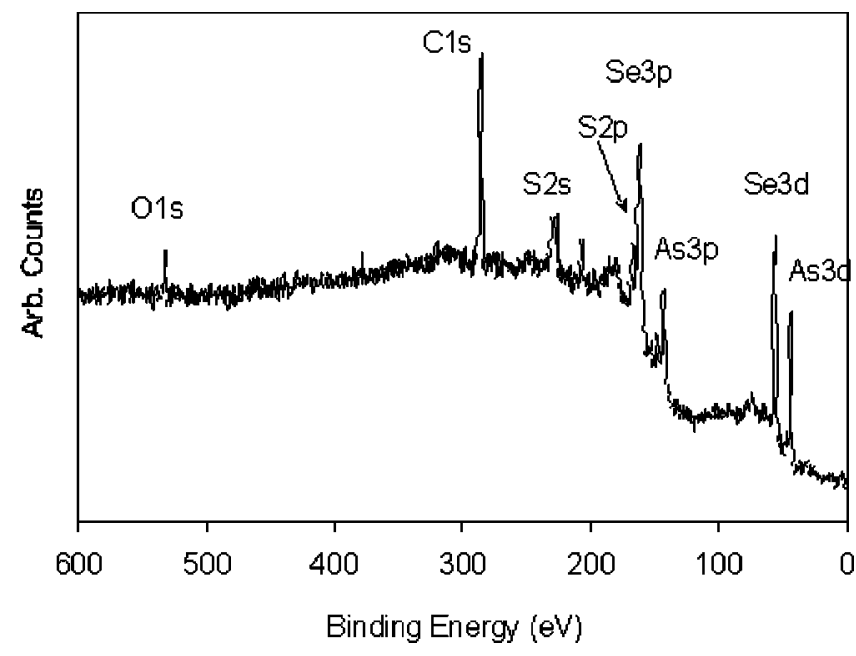

FIG. 2. A typical XPS survey spectra of As-S-Se glass.

\section{B. XPS result of $\mathrm{As}_{24} \mathrm{~S}_{x} \mathrm{Se}_{76-x}$ bulk glasses (x $=0,19,38,57,76$ )}

XPS results of As $3 d$, Se $3 d$, and valence-band spectra of $\mathrm{As}_{24} \mathrm{~S}_{x} \mathrm{Se}_{76-x}$ bulk glasses (specimens 12, 11, 7, 10, 9) are plotted in Figs. 3, 4, and 5.

From As $3 d$ spectra, we observe that in $\mathrm{As}_{24} \mathrm{~S}_{x} \mathrm{Se}_{76-x}$ with $x$ increasing from 0 to 76, the binding energy of As $3 d$ increases from $42.4 \mathrm{eV}\left(\mathrm{As}_{24} \mathrm{Se}_{76}\right)$ to $43.0 \mathrm{eV}\left(\mathrm{As}_{24} \mathrm{~S}_{76}\right)$. Another visible feature in the spectrum is the presence of a satellite peak at $45.0 \mathrm{eV}$. This represents the Se satellite peak. The intensity of this peak increases with increasing Se concentration.

According to Georgiev et al. ${ }^{14}$ the molecular structure of Se-rich As-Se glasses has been widely accepted as a random network of Se chain fragments crosslinked by pyramidal $\mathrm{AsSe}_{3 / 2}$ units. The As site in S-rich As-S glasses has the similar local structure to that in crystalline $\mathrm{As}_{2} \mathrm{~S}_{3}$ (orpiment), only the As-S-As linkages are replaced by As-S-S linkages at higher $\mathrm{S}$ concentration. ${ }^{13}$ With the progressive replacement of Se by S, the atomic environment of As atoms changes from Se to $\mathrm{S}$ surrounding. The local structure of As site changes from As-Se-Se to As-S-Se and then to As$\mathrm{S}-\mathrm{S}$. Because $\mathrm{S}$ is a non-metal and has a higher value of

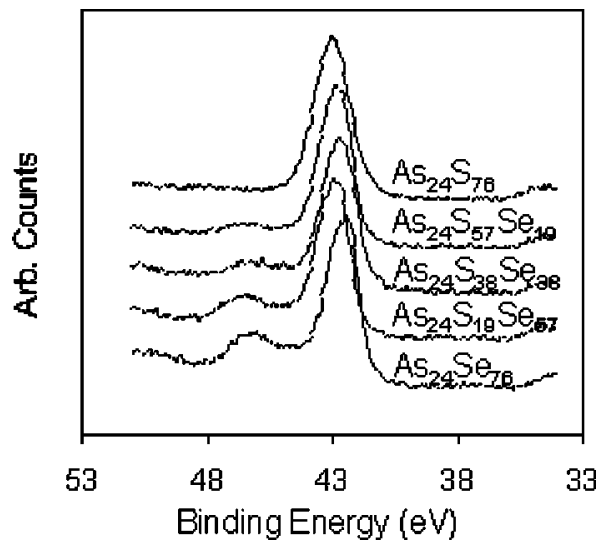

FIG. 3. As $3 d$ peak in As-S-Se bulk samples with fixed As composition.

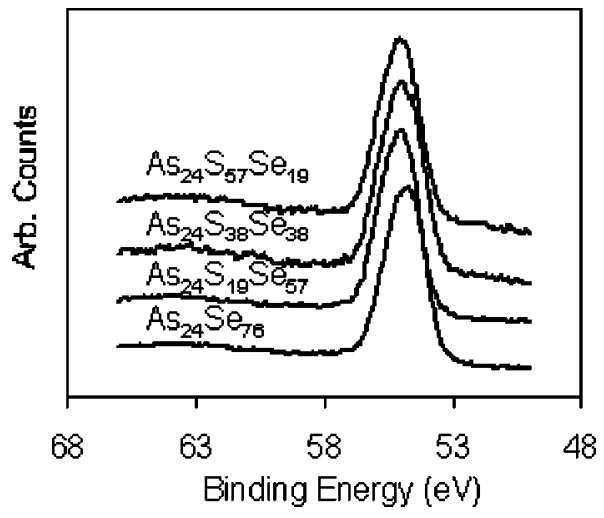

FIG. 4. Se $3 d$ peak in As-S-Se bulk samples with fixed As composition.

electronegativity (2.58) than that of Se $(2.55),{ }^{36}$ the binding energy of As increases.

Figure 4 shows that the binding energy of $\mathrm{Se} 3 d$ peak increases from 54.6 to $55.0 \mathrm{eV}$ as the $\mathrm{S} / \mathrm{Se}$ ratio increases. This is due to the fact that, with the substitution of Se by S, the atomic environment of Se changes from As and Se surrounding to $\mathrm{S}$ surrounding. The local structure of the Se site will change from $\mathrm{As}-\mathrm{Se}-\mathrm{Se}$ to $\mathrm{S}-\mathrm{Se}-\mathrm{Se}$ and then to $\mathrm{S}-\mathrm{Se}-\mathrm{S}$. Because $\mathrm{S}$ has a higher electronegativity (2.58) than both Se (2.55) and As (2.18), ${ }^{36}$ the binding energy of Se increases.

Figure 5 represents the valance-band spectra of $\mathrm{As}_{24} \mathrm{~S}_{x} \mathrm{Se}_{76-x}$ glasses. The valence band of the elemental $\mathrm{Se}$ sample is also detected and plotted. From Fig. 4, it was noticed that, with increasing $\mathrm{Se}$, the two bands located at 2.5 and $5.5 \mathrm{eV}$ become more distinct. Another feature of the valence band is that the band gap $(\Delta \varepsilon)$ increases with an increasing $x$ value, from $x=0 \quad\left(\mathrm{As}_{24} \mathrm{Se}_{76}\right)$ to $x=76$ $\left(\mathrm{As}_{24} \mathrm{~S}_{76}\right)$.

In the elemental Se valence band, the peak at $5.5 \mathrm{eV}$ is associated with the bonding $p$ band $(4 p)$, and the peak at 2.5 $\mathrm{eV}$ with the lone-pair orbitals. ${ }^{37}$ These two features at the valence band of $\mathrm{As}_{24} \mathrm{~S}_{x} \mathrm{Se}_{76-x}$ glass indicate that a considerable amount of $\mathrm{Se}-\mathrm{Se}$ homopolar bonds exist in a chalcogenrich As-S-Se glass system. The structure of homopolar $\mathrm{Se}-\mathrm{Se}$ bonds in the As-S-Se glasses is also identified by Raman spectroscopy. ${ }^{4}$ Meanwhile, the structural analysis

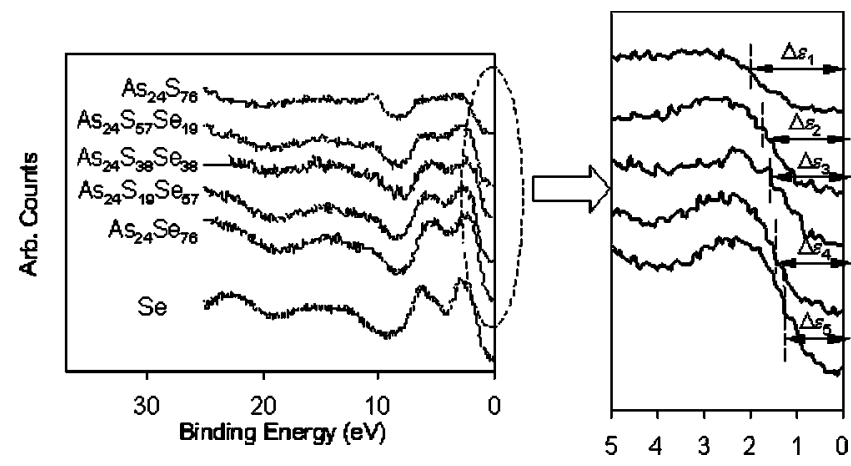

FIG. 5. Valance band in As-S-Se bulk samples with fixed as composition. In the enlarged portion, $\Delta \varepsilon_{1}, \Delta \varepsilon_{2}, \Delta \varepsilon_{3}, \Delta \varepsilon_{4}$, and $\Delta \varepsilon_{5}$ are the estimated band gap for $\mathrm{As}_{24} \mathrm{~S}_{76}, \mathrm{As}_{24} \mathrm{~S}_{57} \mathrm{Se}_{19}, \mathrm{As}_{24} \mathrm{~S}_{38} \mathrm{Se}_{38}, \mathrm{As}_{24} \mathrm{~S}_{19} \mathrm{Se}_{57}$, and $\mathrm{As}_{24} \mathrm{Se}_{76}$, respectively. 


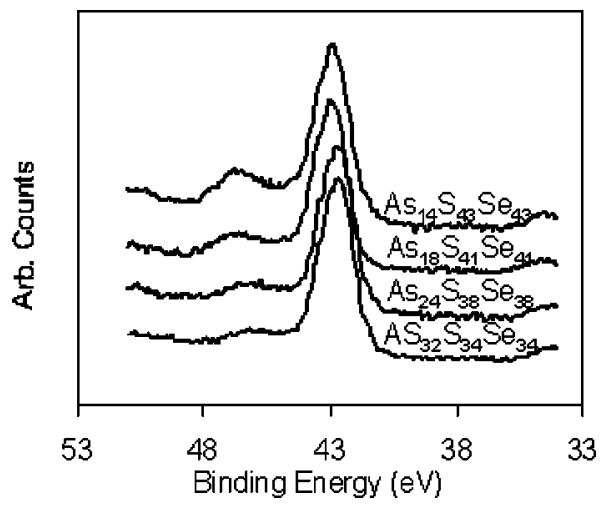

FIG. 6. As $3 d$ peak in As-S-Se bulk samples with fixed S/Se ratio.

shows that the large nonlinear refractive index $n_{2}$ of the sample may be attributed to the excess of $\mathrm{Se}-\mathrm{Se}$ or $\mathrm{Se}-\mathrm{S}$ covalent bonds. This supports the premise that increasing covalency between polarizable atoms increases $n_{2} .{ }^{4,38}$ According to the valence-band spectra of $\mathrm{As}_{24} \mathrm{~S}_{x} \mathrm{Se}_{76-x}$, introducing Se into chalcogen-rich As-S-Se glasses, the amount of $\mathrm{Se}-\mathrm{Se}$ homopolar bands increases, so does the nonlinear property $n_{2}$.

Another important observation we gain from the valance-band data is the band-gap information. The band gap of insulator between the valence band and the empty conduction band can be calculated from the high-resolution XPS result of the valence band after Fermi-level correction. ${ }^{39,40}$ Here, we estimate the band gap at the valence-band leading edge. ${ }^{24}$ We can see an appreciable decrease in the band gap with increasing $\mathrm{Se}$, from about $2.0\left(\mathrm{As}_{24} \mathrm{~S}_{76}\right)$ to $1.4 \mathrm{eV}$ $\left(\mathrm{As}_{24} \mathrm{~S}_{76}\right)$. The corresponding optical band gap, or to be exact, the optical absorption (OA) maximum, instead of the optical absorption edge, ${ }^{40}$ is shifted from 620 to $830 \mathrm{~nm}$ (near IR range).

The OA redshift effect caused by the substitution of $\mathrm{S}$ by Se has an important impact on the IR application of the glasses. Similar results have been observed in the linear optical absorption spectra of the $\mathrm{As}_{40} \mathrm{~S}_{60-x} \mathrm{Se}_{x}$ system. ${ }^{4}$ It is also important to consider band-gap information for higherpower application, where a glass's two-photon absorption (2PA) becomes significant. For use at the telecommunication wavelength of $1.55 \mu \mathrm{m}$, the two-photon energy $(2 \mathrm{~h} \nu)$ is about $1.6 \mathrm{eV}$. Hence, glasses with a band gap near or below this level, may have appreciable 2PA nonlinear absorption that could compromise the materials use in high power applications. ${ }^{41}$ Based on this observation, excessive Se composition should be avoided when we use $\mathrm{As}_{24} \mathrm{~S}_{x} \mathrm{Se}_{76-x}$ glass for high-energy applications. These glasses may have band gaps lower than the 2PA energy.

\section{XPS result of $A s_{100-2 x} S_{x} S_{e}$ bulk glasses $(x=34,38,41,43)$}

XPS results of As $3 d$, Se $3 d$, and valence bands of the $\mathrm{As}_{100-2 x} \mathrm{~S}_{x} \mathrm{Se}_{x}$ bulk glasses (Specimens 6, 7, 8, and 13) are plotted in Figs. 6, 7 and 8.

In Fig. 6, for $\mathrm{As}_{100-2 x} \mathrm{~S}_{x} \mathrm{Se}_{x}$, where $x$ increases from 34 to 43 , with fixed $\mathrm{S} / \mathrm{Se}=1$ and a decrease in As content, the

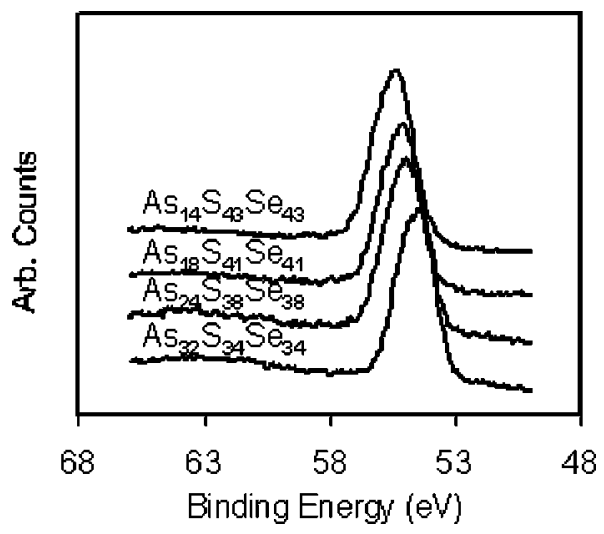

FIG. 7. Se $3 d$ peak in As-S-Se bulk samples with fixed S/Se ratio.

binding energy of As $3 d$ increases from 42.6 to $43.0 \mathrm{eV}$. The Se satellite is also present, and its intensity increases as Se to As ratio increases.

The molecular structure of chalcogen-rich As chalcogenide glass is made of chalcogen chain fragments cross linked by $\mathrm{AsCh}_{3 / 2}$ units. ${ }^{13,14}$ From $\mathrm{As}_{32} \mathrm{~S}_{34} \mathrm{Se}_{34}$ to $\mathrm{As}_{14} \mathrm{~S}_{43} \mathrm{Se}_{43}$, ( $\mathrm{S}$ $+\mathrm{Se}$ )/As ratio increasing from 2.1 to 6.1 , the number of As-containing pyramid units is expected to decrease and chalcogen-chalcogen chain length to increase. It has been observed by Raman spectroscopy that, in chalcogen-rich glasses containing equal amounts of $\mathrm{S}$ and $\mathrm{Se}, \mathrm{S}$ primarily forms As-S bonds and Se forms homopolar Se-Se, or heterpolar S-Se bonds. ${ }^{4}$ As the arsenic content is reduced and the chalcogen molar ratio $\mathrm{Se} / \mathrm{S}$ remains equal to one, the atomic environment of As atom changes from $\mathrm{S}$ and Se surrounding to $S$ surrounding. The local environment of the As site changes from $\mathrm{Se}-\mathrm{As}-\mathrm{S}$ to $\mathrm{S}-\mathrm{As}-\mathrm{S}$. Because $\mathrm{S}$ has a higher electronegativity than Se, the binding energy of As $3 d$ increases.

Figure 7 shows that with increasing $x$, the Se $3 d$ binding energy of $\mathrm{As}_{100-2 x} \mathrm{~S}_{x} \mathrm{Se}_{x}$ increases from $54.5 \mathrm{eV}$ $\left(\mathrm{As}_{32} \mathrm{~S}_{34} \mathrm{Se}_{34}\right)$ to $55.5 \mathrm{eV}\left(\mathrm{As}_{14} \mathrm{~S}_{43} \mathrm{Se}_{43}\right)$. With decreasing As content, the atomic environment of Se changes from As and $\mathrm{S}$ surrounding to $\mathrm{S}$ and $\mathrm{Se}$ surrounding. Hence, the local structure of Se changes from As-Se-S to $\mathrm{S}-\mathrm{Se}-\mathrm{Se}$. That causes the binding energy of Se $3 d$ to increase.

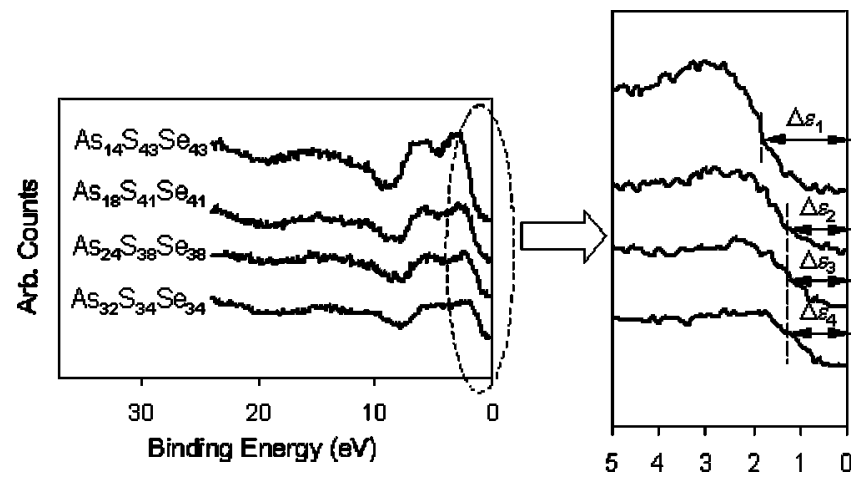

FIG. 8. Valance band in As-S-Se bulk samples with fixed Se/S ratio. In the enlarged portion, $\Delta \varepsilon_{1}, \Delta \varepsilon_{2}, \Delta \varepsilon_{3}$, and $\Delta \varepsilon_{4}$ are the estimated band gap for $\mathrm{As}_{14} \mathrm{~S}_{43} \mathrm{Se}_{43}, \mathrm{As}_{18} \mathrm{~S}_{41} \mathrm{Se}_{41}, \mathrm{As}_{24} \mathrm{~S}_{38} \mathrm{Se}_{38}$, and $\mathrm{As}_{32} \mathrm{~S}_{34} \mathrm{Se}_{34}$, respectively. 
In Fig. 8, with decreased $\mathrm{As}$ and fixed $\mathrm{S} / \mathrm{Se}=1$, the valence-band spectra shows that the two bands located at 2.5 and $5.5 \mathrm{eV}$ become more distinct, a typical characteristic of the elemental Se valence band. This confirms that there will be more $\mathrm{Se}$ in the $\mathrm{Se}-\mathrm{Se}$ and $\mathrm{Se}-\mathrm{S}$ chains with decreasing As, as $\mathrm{S}$ is mainly participating in the $\mathrm{AsS}_{3 / 2}$ pyramidal units.

Unlike in $\mathrm{As}_{24} \mathrm{~S}_{x} \mathrm{Se}_{76-x}$ glasses, there is no clear pattern of the band-gap changes in the $\mathrm{As}_{100-2 x} \mathrm{~S}_{x} \mathrm{Se}_{x}$ system. While the band-gap energies of $\mathrm{As}_{18} \mathrm{~S}_{41} \mathrm{Se}_{41}, \mathrm{As}_{24} \mathrm{~S}_{38} \mathrm{Se}_{38}$, and $\mathrm{As}_{32} \mathrm{~S}_{34} \mathrm{Se}_{34}$ are almost the same, $\mathrm{As}_{14} \mathrm{~S}_{43} \mathrm{Se}_{43}$ seems to have a higher value. Prior optical absorption measurement ${ }^{4}$ also found that the decrease in the molar ratio $\mathrm{As} /(\mathrm{S}+\mathrm{Se})$ has little effect on the linear absorption, and the optical band edge remained in the same wavelength range for $\mathrm{As}_{24} \mathrm{~S}_{38} \mathrm{Se}_{38}, \mathrm{As}_{32} \mathrm{~S}_{34} \mathrm{Se}_{34}$, and $\mathrm{As}_{40} \mathrm{~S}_{30} \mathrm{Se}_{30}$.

In the As-S binary system, a decrease in As/S ratio results in a systematic increase in the band gap. ${ }^{38}$ From $\mathrm{As}_{40} \mathrm{~S}_{30} \mathrm{Se}_{30}$ to $\mathrm{As}_{24} \mathrm{~S}_{38} \mathrm{Se}_{38}$, the As/Ch ratio decreases, however the band gap shows little change. This result can be explained by two factors that compensate each other. First, from $\mathrm{As}_{40} \mathrm{~S}_{30} \mathrm{Se}_{30}$ to $\mathrm{As}_{24} \mathrm{~S}_{38} \mathrm{Se}_{38}$, the decrease in the As/S ratio causes an increase in the band gap. Second, the increase in Se concentration, meaning more $\mathrm{Se}-\mathrm{Se}$ or $\mathrm{Se}-\mathrm{S}$ bonds, ${ }^{4}$ causing a decrease in band gap.

The reason for $\mathrm{As}_{14} \mathrm{~S}_{43} \mathrm{Se}_{43}$ having a higher-band gap than the reference value ${ }^{41}$ is not clear. One possible reason is that the XPS data collection was done on an old sample for this composition. It took longer (more than $30 \mathrm{~min}$ ) to sputter clean the sample. All the other fresh samples required 5-10 min to sputter away most of the surface contamination and achieve good signal-to-noise ratio. The long sputtering time may have affected the sample surface chemistry to induce change in the band gap. It was found that, in the Se sample, $\mathrm{Ar}^{+}$bombardment produced reversible changes of the structure in the XPS valence band which relaxes during a time interval of days. The $4 p$ bonding and the lone-pair orbits tend to merge to one peak at a binding energy close to the lone-pair orbit. ${ }^{42}$ While the lone-pair orbit shifts to a higherbinding energy, the band gap increases. The high-Se composition may cause similar change in $\mathrm{As}_{14} \mathrm{~S}_{43} \mathrm{Se}_{43}$, under ion bombardment, even though the merging of the two peaks is not completed. This could be a reason for the higher-band gap in $\mathrm{As}_{14} \mathrm{~S}_{43} \mathrm{Se}_{43}$.

Another possible reason might be due to the fact that As and $\mathrm{Se}-\mathrm{S}$ bands have different conductivity. As a result, the $\mathrm{As}_{1-x}(\mathrm{SSe})_{x}$ compound will show a change in the band gap with changing $x$ value, especially at the end compositions (As and $\mathrm{S}_{50} \mathrm{Se}_{50}$ ). When the composition is close to $\mathrm{S}_{50} \mathrm{Se}_{50}$, an increase of band gap will occur. This may also explain the higher-band gap in $\mathrm{As}_{14} \mathrm{~S}_{43} \mathrm{Se}_{43}$.

\section{Comparing film and bulk $A s_{100-2 x} S_{x} S_{e}$ samples $(x=34,38,41,43)$}

Thin-film devices based on chalcogenide glasses are attractive for integrated optics applications due to their good infrared transmission and high-nonlinear Kerr effects. ${ }^{43}$ To optimize film properties and device performance, we use XPS to identify the chemical and structural origin of the

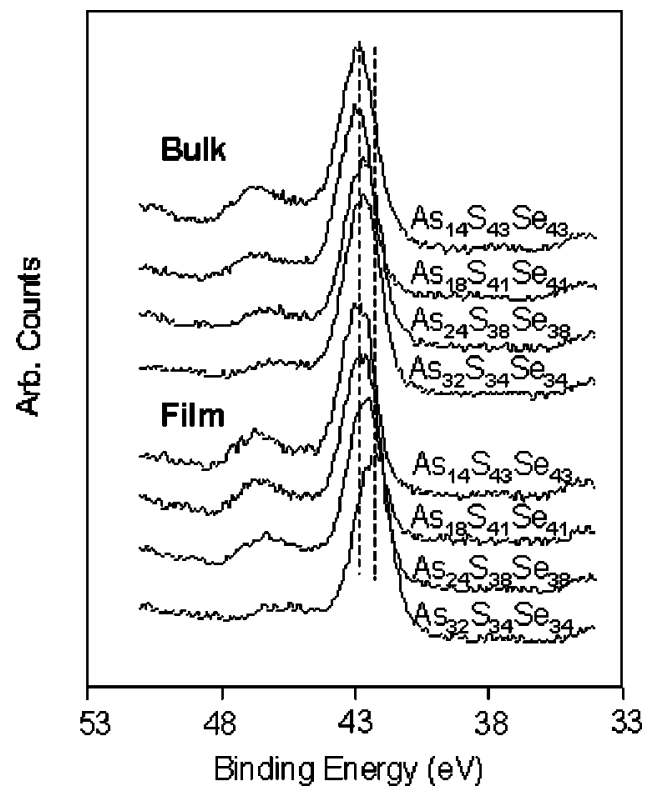

FIG. 9. Comparing As $3 d$ peaks between bulk and film samples with fixed $\mathrm{S} / \mathrm{Se}$ ratio.

thin-film optical properties, and compare it to bulk samples, where the processing conditions are vastly different.

A detailed comparison was made between the bulk and the film samples with fixed S/Se ratios in Figs. 9, 10 and 11. Here, similar trends are observed in film as in bulk, but two distinct differences are observed. First, the two peaks at 2.5 and $5.5 \mathrm{eV}$ in the valance band are more distinct and sharper in film samples. Second, both the binding energies for As $3 d$ and $\mathrm{Se} 3 d$ are slightly lower in the films than in the bulk samples.

The structural difference between bulk and film chalcogenide glasses has been well studied in the As-S and As-Se

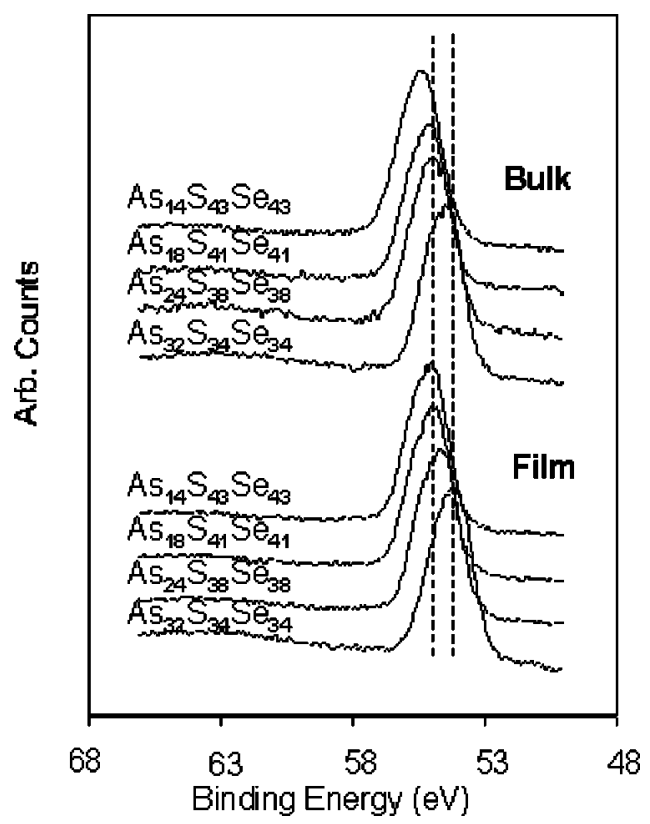

FIG. 10. Comparing Se $3 d$ peaks between bulk and film samples with fixed S/Se ratio. 


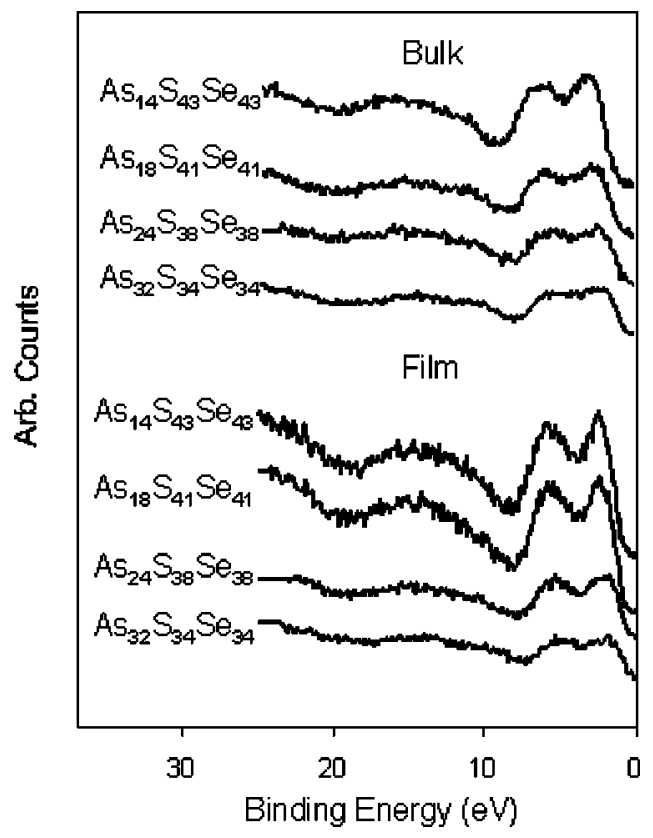

FIG. 11. Comparing valance bands between bulk and film samples with fixed $\mathrm{S} / \mathrm{Se}$ ratio.

binary systems. The x-ray diffraction study shows that the structure of the freshly deposited $\mathrm{As}_{x} \mathrm{Se}_{1-x}$ film differs very significantly from that of the bulk glass. ${ }^{44}$ In $\mathrm{As}_{2} \mathrm{Se}_{3}$ film, optical measurement observed two absorption bands which were interpreted in terms of defect of homopolar bonds. ${ }^{45} \mathrm{In}$ arsenic sulfide film, there is evidence of more As-As bonds; and the films are As rich. ${ }^{46}$ Recent research confirmed that As-S film contains at least $32 \%$ of As-As bonds in the total arsenic bonds, and the amount of As-As bonds decreases after annealing and illumination. ${ }^{47}$

The structural difference between bulk and film AsS-Se ternary glass is rarely studied. The Raman study ${ }^{17}$ on $\mathrm{As}_{40} \mathrm{~S}_{40} \mathrm{Se}_{20}$ suggested that mixed $\mathrm{AsS}(\mathrm{Se})_{3 / 2}$ pyramidal structural units present in the structure of as-evaporated films; the film may contain a significant number of defects such as $\mathrm{As}_{4} \mathrm{~S}(\mathrm{Se})_{4}, \mathrm{~S}(\mathrm{Se})$, and $\mathrm{As}_{4}$ molecular fragments; and there is evidence for As-As bonds.

It is evident from our studies, $\mathrm{As}_{4} \mathrm{~S}(\mathrm{Se})_{4}$ is present in chalcogen-rich As-S-Se glassy films, as $\mathrm{As}_{4} \mathrm{Ch}_{4}$ is the dominant species in the vapor phase. ${ }^{47}$ Earlier Raman study ${ }^{43}$ on chalcogenide film also suggested a similar existence of as-deposited molecular $\mathrm{As}_{4} \mathrm{~S}_{4}$ units. Thus, arsenic atoms in films may possess a lower-coordination number, resulting in a lower As $3 d$ binding energy.

Another effect of the structural difference, is that the network of the glass film is weaker, and more molecular fragments such as $\mathrm{S}(\mathrm{Se})$ and $\mathrm{As}_{4}$ exist. ${ }^{17}$ This means there are more homopolar bonds (As-As, $\mathrm{S}-\mathrm{S}$, and $\mathrm{Se}-\mathrm{Se}$ bonds). That also results in a lower Se $3 d$ binding energy.

Film valence-band results showed that the Se-elemental band structures are more distinct and sharper. These findings confirm that there are more $\mathrm{Se}-\mathrm{Se}$ bands in the films than in the bulk samples (i.e., higher peaks in valence-band features). It also supports the existence of Se molecular fragment (i.e., sharper peaks in valence band). It was found that the excess of $\mathrm{Se}-\mathrm{Se}$ covalent bonds are responsible for the higher nonlinearity in As-S-Se glasses. ${ }^{4}$ As the structure and the composition of evaporated chalcogenide films depends strongly on the preparation conditions of their bulk parent glass and the evaporation conditions, ${ }^{48}$ it is possible to improve the nonlinearity of the As-S-Se films through controlling the conditions of the film formation.

\section{CONCLUSIONS}

In summary, we studied the compositional structural changes in a chalcogen-rich As-S-Se system using As $3 d$, Se $3 d$, and valence-band XPS results from $\mathrm{As}_{24} \mathrm{~S}_{x} \mathrm{Se}_{76-x}$ and $\mathrm{As}_{100-x} \mathrm{~S}_{x} \mathrm{Se}_{x}$ glasses. The following are the important conclusions of this study:

(1) In $\mathrm{As}_{24} \mathrm{~S}_{x} \mathrm{Se}_{76-x}$, with fixed $\mathrm{As}=24 \%$ and Se replaced by S, increasing $x$ results in an increase in the As $3 d$ and $\mathrm{Se} 3 d$ binding energies. At higher Se concentration, a considerable amount of $\mathrm{Se}-\mathrm{Se}$ homopolar bonds exist in the glass. This can result in an appreciable redshift in the optical band gap with increasing Se content.

(2) In $\mathrm{As}_{100-2 x} \mathrm{~S}_{x} \mathrm{Se}_{x}$, with fixed $\mathrm{S} / \mathrm{Se}=1$, decreasing As in the glass, similar increase in the XPS binding energies of As $3 d$ and Se $3 d$ has been observed. At lower As concentration, there are more $\mathrm{Se}-\mathrm{Se}$ bonds in the glass structure. There is no considerable change in the optical band gap caused by changing the As content in $\mathrm{As}_{100-2 x} \mathrm{~S}_{x} \mathrm{Se}_{x}$, from $x=34$ to $x=41$.

(3) The results from the As-S-Se films are similar to that of the bulk glasses, but there are two major differences. First, in the films, the binding energies of both As $3 d$ and Se $3 d$ are slightly lower than those in the bulk samples. Second, the features of Se-Se homopolar bonds are more distinguished and sharp in the films as detected from XPS valence bands. More importantly, this feature shows the evidence of the existence of molecular fragments of $\mathrm{As}_{4} \mathrm{~S}(\mathrm{Se})_{4}, \mathrm{~S}-\mathrm{S}$, and $\mathrm{Se}-\mathrm{Se}$ in the film structure.

${ }^{1}$ R. Frerichs, Phys. Rev. 78, 643 (1950).

${ }^{2}$ R. Frerichs, J. Opt. Soc. Am. 43, 1153 (1953).

${ }^{3}$ A. R. Hilton, J. Non-Cryst. Solids 2, 28 (1970).

${ }^{4}$ T. Cardinal, K. A. Richardson, H. Shim, A. Schulte, R. Beatty, K. Le Foulgoc, C. Meneghini, J. F. Viens, and A. Villeneuve, J. Non-Cryst. Solids 256\&257, 353 (1999).

${ }^{5}$ D. W. Hall, M. A. Newhouse, N. F. Borrelli, W. H. Dumbaugh, and D. L. Weidman, Appl. Phys. Lett. 54, 1293 (1989).

${ }^{6}$ O. M. Efimov, L. B. Glebov, K. A. Richardson, E. Van Stryland, T. Cardinal, S. H. Park, M. Couzi, and J. L. Bruneel, Opt. Mater. 17, 379 (2001).

${ }^{7}$ A. V. Stronski, M. Vlcek, A. Sklenar, P. E. Shepeljavi, S. A. Kostyukevich, and T. Wagner, J. Non-Cryst. Solids 266-269, 973 (2000).

${ }^{8}$ M. Asobe, K. Suzuki, T. Kanamori, and K. Kubodera, Appl. Phys. Lett. 60, 1153 (1992)

${ }^{9}$ A. Saliminia, A. Villeneuve, T. V. Galstyan, S. LaRochelle, and K. Richardson, J. Lightwave Technol. 17, 837 (1999).

${ }^{10}$ W. E. Morgan and J. R. Van Wazer, J. Phys. Chem. 77, 964 (1973).

${ }^{11}$ J. F. Moulder, W. F. Sticker, P. E. Sobol, and K. D. Bomben, Handbook of $X$-ray Photoelectron Spectroscopy (Perkin-Elmer, Eden Prairie, MN, 1992).

${ }^{12} \mathrm{M}$. A. Popescu, Non-Crystalline Chalcogenides (Kluwer Academic, Boston, 2000).

${ }^{13}$ C. Y. Yang, A. A. Paesler, and D. E. Sayers, Phys. Rev. B 39, 10342 (1989), and references within.

${ }^{14}$ D. G. Georgiev, P. Boolahand, and M. Micoulaut, Phys. Rev. B 62, R9228 (2000).

${ }^{15}$ L. G. Protasova, P. I. Buler, and S. A. Subbotina, Inorg. Mater. (Transl. of Neorg. Mater.) 25, 659 (1989). 
${ }^{16}$ J.-L. Wang, J.-C. Tsai, C.-T. Liu, P. Nachimuthu, L.-Y. Jang, R.-G. Liu, and J.-M. Chen, J. Appl. Phys. 88, 2533 (2000).

${ }^{17}$ M. Vlcek, A. V. Stronki, A. Sklenar, T. Wagner, and S. O. Kasap, J. Non-Cryst. Solids 266-269, 964 (2000).

${ }^{18}$ E. Hartouni, F. Hulderman, and T. Guiton, Proc. SPIE 505, 131 (1984).

${ }^{19}$ S. A. Keneman, Thin Solid Films 21, 281 (1974).

${ }^{20}$ A. C. Wright, R. N. Sinclair, and A. J. Leadbetter, J. Non-Cryst. Solids 71, 295 (1985)

${ }^{21}$ P. I. K. Onorato, M. N. Alexander, C. W. Struck, G. W. Tasker, and D. R. Uhlmann, J. Am. Ceram. Soc. Bull. 68, C148 (1985).

${ }^{22}$ J. Heo, J. S. Sanghera, and J. D. Mackenzie, J. Non-Cryst. Solids 101, 23 (1988).

${ }^{23}$ R. M. Almeida, H. Nasu, J. Hoe, and J. D. Mackenzie, J. Mater. Sci. Lett. 6, 701 (1987).

${ }^{24}$ D. Briggs and M. P. Seah, Practical Surface Analysis, 2nd ed. Auger and X-ray Photoelectron Spectroscopy (Wiley, Chichester, England, 1990), Vol. 1.

${ }^{25}$ S. J. Kerber, J. J. Bruckner, K. Wozniak, S. Seal, S. Hardcastle, and T. L. Barr, J. Vac. Sci. Technol. A 14, 1314 (1996).

${ }^{26}$ A. Gheorghiu, I. Lampre, S. Dupont, C. Senemaud, M. A. El Idrissi Raghni, P. E. Lippens, and J. Olivier-Fourcade, J. Alloys Compd. 228, 143 (1995).

${ }^{27}$ E. P. Domashevskaya, V. V. Gorbachev, V. A. Terekhov, V. M. Kashkarov, E. V. Panfilova, and A. V. Shchukarev, J. Electron Spectrosc. Relat. Phenom. 114-116, 901 (2001).

${ }^{28}$ H. Jain, S. Krishnaswami, A. C. Miller, P. Krecmer, S. R. Elliott, and M. Vlcek, J. Non-Cryst. Solids 274, 115 (2000).

${ }^{29}$ L. Jiang, A. G. Fitzgerald, M. J. Rose, K. Christova, and V. Pamukchieva, J. Non-Cryst. Solids 297, 13 (2002).

${ }^{30}$ M. Bruns, H. Klewe-Nebenius, G. Pfennig, E. Bychkov, and H. J. Ache, Surf. Coat. Technol. 97, 707 (1997).
${ }^{31}$ J. Fick, E. J. Knystautas, A. Villeneuve, F. Schiettekatte, S. Roorda, and K. A. Richardson, J. Non-Cryst. Solids 272, 200 (2000).

${ }^{32}$ W. J. Stec, W. E. Morgan, R. G. Albridge, and J. R. Van Wazer, Inorg. Chem. 11, 219 (1972).

${ }^{33}$ W. E. Morgan and J. R. Van Wazer, J. Phys. Chem. 77, 964 (1973).

${ }^{34}$ T. L. Barr and S. Seal, J. Vac. Sci. Technol. A 13, 1239 (1995).

${ }^{35} \mathrm{~B}$. Vincent Crist, Handbook of Monochromatic XPS Spectra-The Elements and Native Oxides (Wiley, New York, 2000), Vol. 1.

${ }^{36}$ CRC Handbook of Chemistry and Physics, edited by David R. Lide, 78th ed. (CRC, Press LLC, Boca Raton, FL, 1997).

${ }^{37}$ N. J. Shevchik, M. Cardona, and J. Tejeda, Phys. Rev. B 8, 2833 (1973).

${ }^{38}$ E. Hajto, P. J. S. Ewen, A. E. Owen, J. Non-Cryst. Solids 164-166, 901 (1993).

${ }^{39}$ G. Martin, S. Strite, A. Botchkarav, A. Agarwal, A. Rockett, H. Morkoc, W. R. Lambrecht, and B. Segall, Appl. Phys. Lett. 65, 610 (1994).

${ }^{40}$ L. S. Lian, M. K. Fung, C. S. Lee, S. T. Lee, M. Inbasekaran, E. P. Woo, and W. W. Wu, Appl. Phys. Lett. 76, 3582 (2000).

${ }^{41}$ A. Schulte and K. Richardson, (unpublished).

${ }^{42}$ B. R. Orton and J. C. Riviere, J. Non-Cryst. Solids 37, 401 (1980).

${ }^{43}$ A. Schulte, C. Rivero, K. Richardson, K. Turcotte, V. Hamel, A. Villeneuve, T. Galstian, and R. Vallee, Opt. Commun. 198, 125 (2001).

${ }^{44}$ A. J. Leadbetter, A. J. Apling, and M. F. Daniel, J. Non-Cryst. Solids 21, 47 (1976).

${ }^{45}$ M. M. El-Ocker, F. Sharaf, and M. K. El-Mously, J. Mater. Sci. 27, 1157 (1992).

${ }^{46}$ A. J. Apling, A. J. Leadbetter, and A. C. Wright, J. Non-Cryst. Solids 23, 369 (1977).

${ }^{47}$ F. Kosek, Z. Cimpl, J. Tulka, and J. Chlebny, J. Non-Cryst. Solids 90, 401 (1987).

${ }^{48}$ T. Bando, D. P. Gosain, S. Okano, and M. Suzuki, Thin Solid Films 195, 237 (1991). 